\title{
LA SEXUALIDAD DE LAS PERSONAS RECLUSAS EN LA JURISPRUDENCIA CONSTITUCIONAL
}

\author{
Juan Luis de Diego Arias
}

doi: 10.18543/ed-63(2)-2015pp225-241

\begin{abstract}
Sumario: 1. De LA VISITA ÍNTIMA A LA VISITA FAMILIAR. 2. LA SEXUALIDAD Y EL LIBRE DESARROLLO DE LA PERSONALIDAD. 3. EL DERECHO A LAS COMUNICACIONES. 4. LAS RELACIONES SEXUALES Y LA INTIMIDAD.
\end{abstract}

\section{DE LA VISITA ÍNTIMA A LA VISITA FAMILIAR}

El Tribunal Constitucional, ha abordado en dos ocasiones, espaciadas por un cuarto de siglo, la cuestión de la sexualidad de las personas que están en prisión (STC 89/1987, de 3 de junio, caso «visita íntima» y STC 128/2013, de 3 de junio, caso «visita familiar»).

En la primera de ellas, dictada hace casi tres décadas, realiza tres importantes afirmaciones, acompañadas de sendas argumentaciones: en primer lugar que la sexualidad se integra en el ámbito de la intimidad; en segundo lugar que el mantenimiento de relaciones sexuales no es contenido de ningún derecho fundamental, y en tercer lugar, que la privación de relaciones sexuales no supone restricción o limitación de derecho fundamental alguno.

Estas declaraciones merecen nuestra atención y nuestro análisis.

La afirmación de que «la sexualidad se integra en el ámbito de la intimidad» es fundamentada por el Tribunal sobre la base de los siguientes puntos:

En primer lugar, la sexualidad pertenece al ámbito de la intimidad, destacando dicho punto al resaltar que la sexualidad pertenece al ámbito de la intimidad, siendo evidentemente uno de sus reductos más sagrados». En segundo lugar que las comunicaciones íntimas son un ámbito de intimidad para las 
personas presas, y así, la autorización para la comunicación íntima restaura circunstancialmente para éstas un ámbito provisional de intimidad» (FJ2). En tercer lugar, que las relaciones íntimas han de celebrarse, cuando resulten autorizadas, en condiciones que salvaguarden la dignidad de las personas, precisamente por las exigencias de lo dispuesto en el art. 18.1 C.E (FJ2).

Esta sentencia es la primera en incluir la sexualidad en el ámbito constitucional de la intimidad. Desde este punto de vista, las comunicaciones íntimas habilitan un ámbito espacio-temporal de intimidad para las personas presas.

Por otra parte, no podemos menos que apuntar que el hecho de calificar de sagrada a la sexualidad supone utilizar un lenguaje religioso, que hoy puede resultar anacrónico para hablar de sexualidad.

La segunda afirmación de la sentencia, efectuada con rotundidad es que «el mantenimiento de relaciones íntimas no forma parte del contenido de ningún derecho fundamental».

De esta afirmación se sigue una conclusión igual de contundente: «su privación no supone limitación ni restricción de derecho fundamental alguno».

Para llegar a estas aserciones la sentencia realiza las siguientes argumentaciones:

«Para quienes se encuentran en libertad, el mantenimiento de estas relaciones no es el ejercicio de un derecho, sino una manifestación más de la multiplicidad de actividades y relaciones vitales que la libertad hace posible. Los derechos fundamentales, que garantiza la libertad, no tienen ni pueden tener como contenido concreto cada una de esas manifestaciones de su práctica, por importantes que éstas sean en la vida del individuo... el mantenimiento de relaciones íntimas no forma parte del contenido de ningún derecho fundamental, por ser, precisamente, una manifestación de la libertad a secas ${ }^{1} \ldots$ Se sigue de ello, claro está, que quienes son privados de ella se ven también impedidos de su práctica sin que ello implique restricción o limitación de derecho fundamental alguno».

Se hace difícil seguir esta argumentación. Parece contemplar la libertad en abstracto, distinguiendo entre la libertad en sí misma, «libertad a secas» la denomina, y los actos libres que son manifestación de la libertad.

En este sentido nos preguntamos: ¿Se puede abstraer la libertad de sus manifestaciones que son los actos libres? ¿Existe la libertad en abstracto, sin la concreción espacio-temporal de dichos actos? A nuestro juicio, la respuesta a todas estas cuestiones debe ser negativa.

De esta primera premisa: «el mantenimiento de relaciones íntimas son una manifestación más de la libertad a secas», se sigue que las mismas no

${ }^{1}$ Esta afirmación es valorada muy críticamente por MARTínEZ DE PISÓN, al apuntar que «no tiene ni pies ni cabeza». MARTínEZ DE PISON, J.: «Vida privada e intimidad: implicaciones y perversiones», en Anuario de Filosofía del Derecho XIV, 1993, p. 733. 
forman parte del contenido de ningún derecho fundamental: «El mantenimiento de relaciones íntimas no forma parte del contenido de ningún derecho fundamental».

La afirmación de que «el mantenimiento de relaciones íntimas no forma parte del contenido de ningún derecho fundamental» significa que la sexualidad y su ejercicio no son objeto de protección constitucional al más alto nivel.

Sobre esta sentencia señala MARTínEZ DE PISÓN que parece que el Tribunal Constitucional «tuviera miedo de afirmar que la vida sexual pertenece a lo más íntimo de la persona, para lo cual se necesita un ámbito, un espacio intocable en el que poder realizarla»; y si la vida sexual no pertenece a la intimidad ¿qué es lo que queda como propio de la intimidad?².

Para este autor la sentencia, además de contener unas consideraciones argumentativas poco convincentes, resulta muy preocupante «pues se produce una limitación jurisprudencial del derecho a la intimidad» y «un reduccionismo injustificado del contenido material de intimidad». Si la declaración de que «las relaciones sexuales entre personas no pertenece al derecho a la intimidad, sino a la libertad a secas» se universaliza a todos los ciudadanos ¿qué pasaría en el supuesto de que una relación sexual mantenida en una habitación fuese captada, filmada o grabada por un tercero? ¿Qué derecho se habría violado?, ¿Se habría lesionado el derecho a la intimidad?, «¿Cabe algún tipo de protección legal ante esos hechos? la necesidad de tener unas relaciones sexuales fluidas no son tenidas en cuenta en esta argumentación» ${ }^{3}$.

\section{LA SEXUALIDAD Y EL LIBRE DESARROLLO DE LA PERSONALIDAD}

Esta realidad humana, tan profunda y rica en matices, no está formulada en nuestra lex suprema como derecho fundamental. Es más ningún artículo hace referencia a la sexualidad. Sólo el sexo, en su acepción de género, se menciona en el artículo 14 que prohíbe la discriminación, en el artículo 35,

2 Ibídem, p. 733; y también MARTínEZ DE PISÓN CAVERo, J.: El derecho a la intimidad en la jurisprudencia constitucional, Cívitas, Madrid, 1993, p. 190.

3 MartíneZ DE Pisón, J. óp. cit. p. 734. En referencia a esta reflexión queremos dejar constancia que la grabación sonora de una visita vis a vis ya ha tenido lugar y ha sido valorada por el Tribunal Supremo, Sala de lo Penal, sección 1, en Auto 6517/2013, de fecha 10 de junio, como una medida razonada y admisible, que hace que la injerencia en el ámbito de la intimidad que representa se entienda como un «sacrificio justificado derivado de la legitimidad de este medio de investigación criminal para avanzar en tal investigación». Esta resolución es criticada por REVIRIEGO PICÓN que considera que «en modo alguno puede autorizarse una grabación de estas características». REVIRIEGO PICÓN, F.: «El derecho a la intimidad y los vis a vis en los centros penitenciarios», Actualidad Juridica Aranzadi n. ${ }^{\circ}$ 860/2013, 2013. 
que prohíbe la discriminación en el ámbito laboral, y en el artículo 57, que regula la sucesión a la Corona.

Sería necesario reflexionar sobre la necesidad de incluir el derecho a la sexualidad en el catálogo de los derechos fundamentales. Por un lado su inclusión podría ser valorada como un paso más en «la huida hacia delante, consistente en la generalizada proclamación formal urbi et orbe de decenas de derechos $»^{4}$. Por otro, en cambio, será tener en cuenta la vocación expansiva de la ética, que como dice ANSUÁTEGUI RoIG es «la que produce la expansión de los derechos y su reconocimiento». Pues son los derechos fundamentales los que en cada momento, traducen jurídicamente las «exigencias morales más importantes» de la dignidad humana» ${ }^{5}$.

De este modo, el reconocimiento del derecho fundamental a la sexualidad, sería tener, en cuenta, por ejemplo, la garantía del ejercicio de la sexualidad para colectivos de personas que carecen de la libertad, la autonomía y las condiciones necesarias para ello. Pensemos en las personas con discapacidad, en las personas mayores o enfermas que viven en una institución, compartiendo habitación. ¿Cómo se preservan las condiciones necesarias para su libertad sexual?

La anterior reflexión supera con creces los límites de esta ponencia; sin embargo, apuntada queda, y mientras se aborda su desarrollo, creemos que la sexualidad y su ejercicio encuentran albergue en el actual texto constitucional.

La sexualidad puede entenderse presente en «el libre desarrollo de la personalidad» (artículo 10.1 CE); en «el derecho a la vida y a la integridad física y moral» (artículo 15); en el artículo 18.1, que garantiza el derecho a la intimidad personal y familiar; y en el derecho al acceso al desarrollo integral de la personalidad que el artículo 25.2 reconoce a los condenados a pena de prisión.

Retomando la sentencia que nos ocupa, y respecto de su afirmación de que «los derechos fundamentales, que garantiza la libertad, no tienen ni pueden tener como contenido concreto cada una de las manifestaciones de su práctica», se podría cuestionar lo siguiente: si las manifestaciones de la práctica de un derecho fundamental no son parte de su contenido, ¿En qué consiste éste? Para nosotros el contenido concreto de un derecho fundamental no es más ni menos que la suma de cada una de sus manifestaciones.

${ }^{4}$ SÁnchez GonzÁlez, S. (Coord.): Dogmática y práctica de los derechos fundamentales, Tirant lo Blanc, Valencia, 2006, p. 18.

5 Ansuátegui Roig, F. J.: «Derechos, Constitución, Democracia y libertades en la España del Antiguo Régimen». En Pérez-Prendes Muñoz-Arraco, J.M.; Coronas GonzÁlez, S.M.; AnsuÁtegui Roig, F.J. y Bilbao, J.M.: Derechos y libertades en la historia, Secretariado de publicaciones e intercambio editorial, Universidad de Valladolid, 2003, pp. 175 y 178 . 
Los razonamientos del Tribunal son muy forzados y llevan al vaciamiento de contenido al derecho del recluso a las comunicaciones, pues como dice Martínez Escamilla, el anterior argumento «no sólo sería aplicable a la denegación de visitas íntimas, sino también a la denegación de cualquier comunicación con familiares o amigos», pues tales comunicaciones tampoco serían, en expresión del Tribunal Constitucional, un derecho en sí mismo considerado, sino una manifestación más de la libertad, de la que el preso ha sido privado. De esta manera «la denegación arbitraria de la comunicación con un familiar o amigo no lesionaría derecho fundamental alguno» ${ }^{6}$.

A la misma conclusión llega DELGADO DEL RINCÓN que afirma que «aunque la STC 89/1987, de 3 de junio, se haya dictado exclusivamente respecto de las comunicaciones íntimas de los presos» la argumentación utilizada podría extenderse igualmente a las comunicaciones familiares y de convivencia, «ya que éstas tampoco se conciben como un derecho en sí mismo considerado, sino tan solo como manifestaciones vitales de la libertad genérica» ${ }^{7}$.

La última argumentación de la sentencia estudiada es la siguiente «quienes son privados de la libertad se ven también impedidos de la práctica de las relaciones sexuales, sin que ello implique restricción o limitación de derecho fundamental alguno».

La anterior aseveración se complementa con la declaración de que la autorización para una comunicación íntima, con la consiguiente restauración episódica de un ámbito provisional de intimidad, es «resultado de una concesión del legislador, no un imperativo derivado del derecho fundamental a la intimidad».

El Tribunal parece contradecirse. Comenzaba su fundamentación diciendo que «la sexualidad pertenece al ámbito de la intimidad, que es incluso uno de sus reductos más sagrados». Lo que puede interpretarse en el sentido de que las relaciones sexuales, como manifestación de la sexualidad, se integran en la intimidad y por lo tanto son objeto o contenido de este derecho fundamental; $y$ en consecuencia su privación es una limitación y una restricción de la sexualidad y por ende del derecho fundamental ${ }^{8}$.

${ }^{6}$ Martínez Escamilla, M.: La suspensión e intervención de las comunicaciones del preso, Tecnos, Madrid, 2000, pp. 33 y 34.

7 Delgado Del Rincón, L.: «Algunas consideraciones sobre el derecho a la intimidad personal y familiar de los presos en los centros penitenciarios», Teoría y realidad constitucional, n. ${ }^{\circ} 18,2006$, p. 218.

${ }^{8}$ La Asociación Mundial de Sexología en el XIV Congreso Mundial de Sexología, celebrado en Hong Kong en 1999, aprobó la Declaración de los derechos sexuales, en la que se puede leer que «La sexualidad es una parte integral de la personalidad de todo ser humano. Su desarrollo pleno depende de necesidades humanas básicas como el deseo de contacto, intimidad, expresión emocional, placer, ternura y amor...El desarrollo pleno de 
Después de alabar que el legislador haya autorizado las comunicaciones íntimas y de volver a recordar que no son objeto de derecho fundamental alguno, la sentencia se dedica a reflexionar sobre la sexualidad humana.

Y lo hace partiendo de la reflexión de que «es, sin duda, plausible, concorde con el espíritu de nuestro tiempo y adecuado a las finalidades que el art. 25.2 asigna a las penas privativas de libertad, que el legislador las autorice, pero ni está obligado a ello ni la creación legal transforma en derecho fundamental de los reclusos la posibilidad de comunicación íntima con sus familiares o allegados íntimos».

A lo que añadirá que «la sexualidad sea parte importante de la vida del hombre es, desde luego, afirmación que puede ser asumida sin reparo, pero de ello no se sigue, en modo alguno, que la abstinencia sexual aceptada por decisión propia, o resultado de la privación legal de libertad, ponga en peligro la integridad física o moral del abstinente, tanto más cuanto se trata de una abstinencia temporal».

De igual forma que la imposibilidad de mantener relaciones sexuales no conduce a que ello suponga «la sumisión a un trato inhumano o degradante».

Y concluye el Alto Tribunal con la afirmación de que «la privación de libertad, como preso o como penado, es, sin duda, un mal, pero de él forma parte, sin agravarlo de forma especial, la privación sexual»»?

La atenta lectura de las anteriores declaraciones nos sugiere la reflexión de que la sexualidad humana es una realidad profunda, rica y llena de matices, y, como tal, objeto de estudio por parte de distintas ciencias y disciplinas. En este sentido Marina llama sexualidad al universo simbólico construido sobre la realidad biológica del sexo, que es «una complicada mezcla de estructuras fisiológicas, conductas, experiencias, sentimentalizaciones, interpretaciones, formas sociales, juegos de poder» ${ }^{10}$.

De modo que el jurista no puede acercarse a un fenómeno de tal naturaleza desde sus creencias personales y desde la mera intuición, antes al contrario, debe de hacer el esfuerzo de estudiar la realidad con la objetividad que le proporciona el método científico desarrollado por las ciencias especializadas. Una vez realizada esta tarea, podrá dar una respuesta jurídica adecuada ${ }^{11}$.

la sexualidad es esencial para el bienestar individual, interpersonal y social. Los derechos sexuales son derechos humanos universales basados en la libertad, dignidad e igualdad inherentes a todos los seres humanos. Dado que la salud es un derecho humano fundamental, la salud sexual debe ser un derecho humano básico». Asociación Mundial de Sexología (2011) Declaración de los derechos sexuales. Cuadernos de Pedagogía 414, p. 23.

9 STC 89/1987, de 3 de junio de 1987, FJ 2.

${ }_{10}$ Marina, J.A.: El rompecabezas de la sexualidad. Anagrama, Barcelona, 2002, p. 31.

11 En este sentido véase MuÑoz SABATÉ, L.: Sexualidad y derecho, Barcelona, Hispano-europea, 1976. 
Desde la Psicología, CARCEDo GonZÁLEZ recuerda como cuestión pacífica que la sexualidad es una de las necesidades básicas del ser humano, la cual ha de ser resuelta si se quiere conseguir un buen estado de satisfacción personal. Tener una buena salud general conlleva tener una buena salud sexual. La afectividad y la sexualidad nos hacen relacionarnos con otros, aumentan nuestra autoestima, nos permiten dar y recibir placer; todo ello coadyuva a nuestro bienestar y a nuestra salud, tanto física como psíquica ${ }^{12}$.

Como dice CAFFARA, la sexualidad es una dimensión de la persona que le hace capaz de salir de sí «hasta la suprema realización de este éxodo de sí» que es el don de sí mismo al otro, el cual crea comunión ${ }^{13}$.

Desde un punto de vista antropológico ${ }^{14}$, el cuerpo y la sexualidad son expresión de la viva totalidad del ser, que más allá de lo puramente biológico, se insertan en el horizonte de la libertad humana.

Visto lo anterior, se puede afirmar que, quizás unas líneas de un fundamento jurídico de una sentencia constitucional no sean el lugar más adecuado para concluir, tan rotundamente, sobre un tema de tal complejidad como la sexualidad humana.

Lo que sí es competencia y objeto del Derecho, ante la declaración de que la comunicación íntima no es un derecho fundamental, es determinar la naturaleza de las comunicaciones y visitas contempladas en el título VIII LOGP.

GARCÍA VALDÉS, al poco de aprobarse el texto constitucional, sostenía que una correcta interpretación del artículo 53 LOGP lleva a considerar su contenido como la expresión de un derecho limitado de los internos, pues «sistemáticamente no puede entenderse como mera recompensa o beneficio penitenciario» los cuales sólo se contienen en el artículo 46 «único que conforma el Capítulo V de la Ley, a tal extremo dedicado» ${ }^{15}$.

GARRIDO GuZMÁn decía, meses antes de que se fallara la sentencia que nos ocupa, que aunque la doctrina es unánime en considerar estos contactos exteriores como un derecho de los internos «se echa en falta que la LOGP no contenga un precepto donde se recoja sistemática y ordenadamente el status jurídico de los reclusos» ${ }^{16}$.

${ }^{12}$ Carcedo GonzÁlez, R. J.: «El estudio de la sexualidad de los varones en prisión», en Pérez Álvarez, S.: In memoriam Alexandri Baratta, Universidad de Salamanca, 2004, p. 297.

13 Caffarra, C.: La sexualidad humana, Encuentro, Madrid, 1987, p. 29.

14 Madrigal Terrazas, S.: «Introducción», en Torre, JAVIER DE LA (Ed.): Sexo, sexualidad y bioética, Madrid, Comillas, 2008, p.18.

15 García Valdés, C.: Comentarios a la legislación penitenciaria. Civitas, Madrid, 1982, p. 179.

16 Garrido Guzmán, L.: «Comunicaciones y visitas». En Cobo del Rosal, M. (Dir.) Comentarios a la legislación penal, Tomo VI, vol. 2, Edersa, Madrid, 1986, pp. 742 y 743 . 
Creemos que esta laguna ha sido colmada claramente por la redacción del vigente Reglamento Penitenciario que en su artículo 4.2 e) declara que entre los derechos de los internos se cuenta el «derecho a las relaciones con el exterior previstas en la legislación».

\section{EL DERECHO A LAS COMUNICACIONES}

La jurisprudencia constitucional ya ha reconocido las comunicaciones como derecho. Así la sentencia 200/1997, de 24 de noviembre, FJ3, dice expresamente que «el art. 51 de la Ley Orgánica General Penitenciaria reconoce el derecho de los reclusos a las comunicaciones». En el mismo sentido la sentencia 201/1997, de 25 de noviembre, FJ5, (sentencia de la intimidad familiar, donde se debatía sobre una comunicación telefónica), donde se habla de «tener en cuenta los derechos del recluso, en este supuesto su derecho a la intimidad familiar».

Aún antes de la vigente redacción reglamentaria, la interpretación sistemática y teleológica de la legislación penitenciaria, así como de los principios que la inspiran, permitían concluir que las comunicaciones y visitas son un derecho de los internos.

Así se desprende tanto del artículo $25,2{ }^{\circ} \mathrm{CE}$ que reconoce el goce de los derechos, como del artículo 3 de la LOGP, que señala el respeto de los derechos de los recluidos como principio de la actividad penitenciaria y señala que «los internos podrán ejercitar los derechos civiles, políticos, sociales, económicos y culturales».

Ya de manera expresa el capítulo VIII de la LOGP titulado «Comunicaciones y visitas» llega a formular como derecho el de todo interno «a comunicar inmediatamente a su familia y abogado su detención, así como a comunicar su traslado a otro establecimiento en el momento de ingresar en el mismo» (art. 52.3).

De todo ello se deduce que, tanto los principios generales de nuestro sistema penitenciario, como los preceptos legales transcritos, permiten hablar de un derecho de los internos a mantener contactos con el exterior, a través de comunicaciones y visitas en los establecimientos penitenciarios con sus familiares, amigos y profesionales.

En relación con la visita íntima y su naturaleza jurídica se puede mantener con Garrido Guzmán que «se trata de un derecho del recluso que puede ejercitar para satisfacer sus necesidades sexuales y afectivas $\rangle^{17}$.

Para Dugue Villanueva la doctrina del Tribunal Constitucional, manifestada en la Sentencia 89/1987, de 3 de junio, contrasta con la jurisprudencia

${ }^{17}$ GARrido GuZMÁN, L.: op. cit. pp. 742 y 743. 
del TEDH y de la CEDH, que incluyen en el derecho al respeto de la vida privada y familiar, las visitas y las relaciones de las personas privadas de libertad con sus familiares ${ }^{18}$.

MARTÍNEZ RIDAURA, por su parte, señala que la LOGP contempla las visitas íntimas como una consecuencia de la previsión constitucional del art. 25.2 y, más concretamente, como una manifestación o exigencia del desarrollo integral de la personalidad. Para la LOGP la naturaleza jurídica de la visita íntima es la de un derecho de los internos, «aunque condicionado por la relación penitenciaria, pero, en todo caso, un derecho. Y ello a pesar de la tesis mantenida por el Tribunal Constitucional en este punto» ${ }^{19}$.

GonZÁlez NAVARRo se inclina «tanto desde el punto de vista teórico, como desde el legal español, en favor de considerar que estamos en presencia de un verdadero derecho del interno», porque el recluso tiene derecho al desarrollo integral de su personalidad y «parece que dentro de ese desarrollo integral hay que situar, entre otras muchas cosas, el desarrollo de una vida sexual plena $\rangle^{20}$.

En el otro extremo se sitúa MEDINA GuERRERo, para el que el derecho a tener comunicaciones íntimas no forma parte del contenido de los derechos fundamentales con los que se relacionan en cada caso. Sino que es una facultad creada por el legislador; algo así como un derecho suplementario «que, si bien relacionado con el bien jurídico incorporado en el derecho fundamental de que se trate», no mantiene una conexión directa y necesaria con el mismo,

${ }_{18}$ En este sentido dice DuQue VILLANUEVA que «Así, el TEDH si bien tiene declarado que, respecto de las obligaciones que el art. 8 del CEDH impone a los Estados contratantes en relación con las visitas en las prisiones, hay que tener en cuenta las normales y razonables exigencias de la reclusión y la facultad discrecional que se debe conceder a las autoridades nacionales para regular las relaciones del preso con su familia, reconoce que la situación especial de un preso puede suscitar en el ámbito del art. CEDH una pretensión defendible en relación con las visitas y aboga por aplicar a los reclusos un régimen uniforme, evitando cualquier apariencia de una medida arbitraria o discriminatoria (sentencia de 27 de abril de 1988 -caso Boyle y Rice-)» y «En el mismo sentido, la CEDH entiende que el derecho al respeto de la vida privada de los presos implica el mantenimiento de contactos con el mundo exterior de cara a su integración en la sociedad (D 9054/80 (RU) 8 de octubre de 1982)». DuQue VILlanueVA, J. C.: «El derecho a la intimidad personal y familiar en el ámbito penitenciario», en López OrTega, J. J. (Dir.): Perfiles del Derecho Constitucional en la vida privada y familiar, Consejo General del Poder Judicial, Madrid, 1996, pp. 128 y 129.

19 MARTÍNEZ RIDAURA, «El derecho a las comunicaciones en centros penitenciarios», en LóPez Guerra, L. (Coord.): Estudios de Derecho Constitucional. Homenaje al profesor Dr. D. Joaquín García Morillo, 2001, p. 203.

${ }^{20}$ GonZÁlez NAVArRo, F.: «Poder domesticador del Estado y derechos del recluso», en Martí-Retortillo, S. (Coord.): Estudios sobre la Constitución española. Homenaje al profesor Eduardo García de Enterría, Cívitas, Madrid, 1991, p. 1153. 
por lo que no puede estimarse integrante «del ámbito protegido por la Constitución ${ }^{21}$. Cuestión distinta es la ausencia de referencia expresa en la legislación penitenciaria, a la sexualidad de los presos, su ejercicio y eventual derecho al mismo, aunque el debate sobre este asunto es antiguo.

Como recuerda REVIRIEGo PICÓN las comunicaciones de carácter íntimo fue una cuestión que estuvo muy presente durante la propia tramitación del texto constitucional. El ejercicio de la sexualidad como derecho del recluso se pretendió incluir en el contenido del que terminaría siendo artículo 25, y en última instancia, aquella referencia se terminó difuminando en la más amplia reseña al desarrollo integral de la personalidad $»^{22}$.

Así fue, el ejercicio de la sexualidad por parte de las personas presas fue objeto de una enmienda, la número 64 , al entonces artículo 24 , precedente del actual artículo 25, en el proyecto de Constitución (Ponencia) en el seno de la Comisión de Asuntos constitucionales y libertades públicas.

La enmienda fue propuesta por el diputado LeTAMENDía Belzunce y consistía en añadir a «El condenado a pena de prisión que estuviere cumpliendo la misma gozará de todos los derechos fundamentales garantizados en este capítulo», el siguiente texto «especialmente los de acceso a la cultura y ejercicio de la sexualidad».

Se fundamentaba la enmienda en el hecho de que el acceso a la cultura estaba reconocido como tal derecho en dicho capítulo pero no así el ejercicio libre de la sexualidad: «la no inclusión de esta expresión significa, ni más ni menos, que la continuación de la situación a la que se ve sometido el preso en los establecimientos penitenciarios: el hecho de no poder realizar una sexualidad normal».

En apoyo de su enmienda alegaba que el principio del desarrollo de la libre sexualidad había sido recogido en el dictamen emitido por la Comisión Especial de investigación sobre la situación de establecimientos penitenciarios y aprobado por tal comisión. El Dictamen contemplaba este derecho a la sexualidad, señalando que «la privación de libertad del individuo no implica necesariamente la prohibición de libre ejercicio y desarrollo de libertad de sexualidad, por lo que, en el caso del régimen cerrado o de prisión, se cuidará de que los reclusos puedan mantener periódicas relaciones sexuales» ${ }^{23}$.

${ }^{21}$ Medina Guerrero, M.: La vinculación negativa del legislador a los derechos fundamentales, McGraw-Hill, Madrid, 1996, p. 37.

22 Reviriego Picón, F. (2008): Los derechos de los reclusos en la jurisprudencia constitucional, Universitas, Madrid, p. 87 (con nota de Diario de Sesiones del Senado, n. ${ }^{\circ} 44$, de 25 de agosto de 1978, págs. 3476 y ss.). De este mismo autor, más recientemente «Istituti penitenziari e diritti fondamentali», Percorsi costituzional1, 2015, pp. 141 y ss.

${ }^{23}$ Diario de sesiones del Congreso de los Diputados, año 1978, $\mathrm{n}^{\circ} 71$ de 22 de mayo de 1978 . 
La expresión que finalmente se adoptó fue la conocida de «desarrollo integral de su personalidad», fórmula genérica pero en la que según GARRIDO GUZMÁN, cabe la inclusión del derecho de los mismos a mantener relaciones sexuales; derecho «asumido por nuestro Estado de Derecho que ha optado por la tarea de procurar en sus establecimientos penitenciarios la resocialización de los reclusos» ${ }^{24}$.

También MARTínez DE PISÓN considera que el desarrollo de una vida sexual es un derecho pleno del interno, derivado del derecho que ostenta a desarrollar su vida integralmente, según especificación del artículo $25.2 \mathrm{CE}^{25}$

Otro argumento para considerar las comunicaciones y visitas como contenido de derecho fundamental es la importancia que revisten para la reinserción y resocialización de los internos.

En este sentido el Reglamento penitenciario dice en su artículo 4.2 e) que los internos tendrán derecho a las relaciones con el exterior previstas en la legislación; y en el Artículo 110 c) señala como elemento del tratamiento para la consecución de la finalidad resocializadora de la pena privativa de libertad, la potenciación y facilitación de los «contactos del interno con el exterior contando, siempre que sea posible, con los recursos de la comunidad como instrumentos fundamentales en las tareas de reinserción».

La incidencia positiva que en la reinserción supone el mantenimiento de una buena vida interpersonal y sexual, durante el tiempo en prisión, ha sido puesta de manifiesto, de forma clara, por estudios psicológicos con amplios trabajos de campo ${ }^{26}$.

Tampoco debemos olvidar que cuando una persona presa mantiene una relación afectivo-sexual con otra persona que está en libertad, la privación de libertad no afecta sólo a la vida sexual del interno, sino también a la de su pareja. A este respecto GARCíA VALDÉs llama la atención sobre el problema sexual que al cónyuge que permanece en libertad, crea la ausencia del marido o de la mujer ${ }^{27}$. Y MAPELLI CAFFARENA señala las repercusiones negativas que la falta de normalidad en los contactos conlleva para las relaciones con el cónyuge en libertad ${ }^{28}$.

${ }^{24}$ Garrido Guzmán, L.: «La visita íntima», en Cobo del Rosal, M. (Dir.), Comentarios a la legislación penal, Edersa, Madrid, 1986, pp. 792 y 793.

${ }^{25}$ Martínez de Pisón Cavero, J.: op. cit., p. 189.

${ }^{26}$ Carcedo González, R.J.; López Sánchez, F.; Orgaz Baz, M.B. y Fernández Rouco, N.: «Incidencia de la vida en prisión sobre las necesidades sociales, emocionales y sexuales de los presos, su salud psicológica y reinserción», en CARCEDO GONZÁLEZ, R.J. y REVIRIEGo PICÓN, F. (Eds.): Reinserción, derechos y tratamiento en los centros penitenciarios, Amaru, Salamanca, 2007, p. 76.

${ }^{27}$ GARCía VAldÉs, A.: «Soluciones propuestas al problema sexual de las prisiones», Cuadernos de política criminal 11, 1980, p. 94.

28 Mapelli Caffarena, B.: Principios fundamentales del sistema penitenciario español, Bosch, Barcelona, 1983, p. 208. 
La propia denominación de las visitas como «íntimas» nos puede llevar a deducir que el legislador ha querido incluir el mantenimiento de relaciones sexuales como contenido del derecho fundamental a la intimidad.

En la legislación penitenciaria, Título VIII de la LOGP, hemos visto cómo el principio de máximo respeto a la intimidad rige en todas las clases de comunicaciones; sin embargo, cuando regula las visitas de familiares y allegados íntimos a aquellos internos que no pueden obtener permisos de salida, art. 53 LOGP, de entre todas las clases de estas visitas, sólo adjetiva de «íntimas» aquellas que propician las relaciones sexuales, denominando a las otras dos como «visitas familiares» y «visitas de convivencia» respectivamente (art. 45 RP).

Parece claro que el posible contenido sexual de una comunicación se incluye en el mayor grado de intimidad posible ${ }^{29}$. Por tanto, si las comunicaciones son un derecho de los internos, que habilita para éste un espacio y un tiempo reservados frente a la acción y conocimiento de los demás, se puede sostener que las comunicaciones son ejercicio del derecho fundamental de intimidad, y dentro de ellas las visitas de contenido sexual, la máxima expresión de este derecho.

GARRIDO GUZMÁN mantiene esta misma opinión, cuando dice que la elección del término visita íntima no es caprichosa y es el más omnicomprensivo de todos, puesto que «la esencia de este tipo de contactos del recluso con el exterior descansa en la intimidad de la relación». Por otra parte, la denominación «visita íntima» permite la inclusión en este tipo de comunicaciones tanto los contactos conyugales como los extraconyugales, «solución que parece más acorde con los principios de la moral sexual dominante en nuestros días» ${ }^{30}$.

La sentencia continua con una peculiar visión del derecho de intimidad. Dice que «Lo que el Derecho puede proteger, y el nuestro, afortunadamente, protege, es la intimidad misma, no las acciones privadas e íntimas de los hombres» (FJ2). Al glosar esta afirmación, se pregunta MARTínEZ DE PISÓN: Pues, entonces, ¿qué protege ${ }^{31}$

${ }^{29}$ En este sentido dice Nistal Burón que «Por razones obvias, siendo uno de los principios básicos de las comunicaciones y visitas de los internos, como hemos apuntado, el respeto a la intimidad de los comunicantes, este principio adquiere especial carta de naturaleza en este tipo de comunicaciones -visitas íntimas vis a vis- en las que los comunicantes pueden mantener relaciones sexuales, que requieren quedar amparadas por un mayor respeto, si cabe, a esa intimidad». NISTAL BURÓN, J.: «La intervención de las comunicaciones penitenciarias íntimas "vis a vis". La posible afectación de la intimidad relativa a las relaciones sexuales de los reclusos», Revista Aranzadi Doctrinal, n. ${ }^{\circ}$ 1, 2013, págs.83-91.

${ }^{30}$ Garrido GuzMán, L.: La visita íntima...óp. cit. pp. 784, 792 y 793.

31 Martínez de Pisón Cavero, J.: óp. cit. p. 192. 
Este razonamiento recuerda al efectuado anteriormente respecto de la libertad y sus manifestaciones; se dice que «el derecho protege la intimidad misma no las acciones íntimas de los hombres». Se distingue así la intimidad de las acciones íntimas. ¿Es que existe la intimidad en abstracto? ¿Existe la intimidad sin las acciones íntimas que son su manifestación? ¿No sería más correcto haber dicho «el Derecho protege la intimidad de las acciones privadas e íntimas de los hombres»? Otra vez nos parece un razonamiento abstracto que conduce al vaciamiento de sentido del derecho a la intimidad, al abstraerla de sus facultades que son su expresión en la realidad espacio-temporal.

En este sentido tanto ABA CATOIRA como MEDINA GUERRERO consideran que los derechos fundamentales son derechos subjetivos, y como tales su ejercicio consiste en actuar las facultades o poderes que lo integran. ${ }^{32}$. El contenido constitucionalmente protegido de un derecho fundamental son esos concretos poderes y facultades «en cuanto manifestaciones o proyecciones del bien jurídico a cuya tutela se encomienda el derecho fundamental» ${ }^{33}$.

Por último el Alto Tribunal hace la siguiente declaración: La privación temporal de relaciones íntimas con personas en libertad no viola la intimidad porque es una medida que no la reduce más allá de lo que la ordenada en prisión requiere.

A esta conclusión llega el Juzgador constitucional, aplicando el siguiente silogismo:

Premisa mayor: «Se pueden, tal vez, considerar ilegítimas, como violación de la intimidad y por eso también degradantes, aquellas medidas que la reduzcan más allá de lo que la ordenada vida de la prisión requiere»; es decir que las medidas que reduzcan la intimidad más allá de lo que la ordenada vida en prisión requiere pueden considerarse ilegítimas como violación de la intimidad.

Premisa menor: «Pero esa condición no se da en la restricción o privación temporal de las relaciones íntimas con personas en libertad»; o lo que es lo mismo, que la privación temporal de las relaciones íntimas con personas en libertad no reducen la intimidad más de lo que la ordenada vida en prisión requiere.

Conclusión: «La restricción o privación temporal de las relaciones íntimas con personas en libertad no viola la intimidad pues es una medida que no la reduce más allá de lo que la ordenada vida de la prisión requiere»; es decir que la privación temporal de las relaciones íntimas con personas en libertad no viola la intimidad.

32 ABA CATOIRA, A.: La limitación de los derechos fundamentales por razón del sujeto. Los parlamentarios, los funcionarios y los reclusos, Tecnos, Madrid, 2001, pp. 26, 27 y 28 .

33 Medina Guerrero, M.: óp. cit, p. 11. 
Este razonamiento es de difícil comprensión dado como utiliza el argumento de la ordenada vida en prisión.

La ordenada vida en prisión se utiliza en la jurisprudencia constitucional como límite a la reducción de la intimidad. Es decir que la intimidad no se puede reducir más allá de lo que requiere una ordenada vida en prisión ${ }^{34}$ (sentencia 57/1994, de 28 de febrero, FJ5).

Como dice la sentencia 57/1994, de 28 de febrero, FJ 8 «ha de declararse que las medidas aquí impugnadas por el recurrente han lesionado su derecho a la intimidad personal, cuyo ámbito se ha visto innecesariamente restringido más allá de lo que la ordenada vida en prisión requiere, afectando a su dignidad personal. Lo que ha de conducir, por tanto, al otorgamiento del amparo solicitado». En el mismo sentido SSTC 195/1995, de 19 de diciembre, FJ 3 y 89/2006, de 27 de marzo, FJ 2).

Sin embargo aquí se utiliza para negar la celebración de visitas íntimas y en consecuencia la posibilidad de mantener relaciones sexuales. Esta negación es un límite a la intimidad pues las relaciones sexuales son expresión de la máxima intimidad, y, como tal negación supone la consiguiente reducción de la intimidad.

Para MARTínEZ DE PISÓN la sentencia «hace peligrar» el mismo concepto de intimidad, pues de sus razonamientos se desprende no ya que el desarrollo de una vida sexual pertenece al ámbito de la intimidad, sino que «ni siquiera es una condición para el pleno ejercicio de la integridad moral del individuo ${ }^{35}$.

La fundamentación de la negación de visitas íntimas no puede consistir en «que su privación no reduce la intimidad más allá de lo que la ordenada en prisión requiere»; sino, en todo caso, en aras de una ordenada vida en prisión; es decir, que la celebración de visitas íntimas pusiera en peligro el orden, la seguridad del establecimiento o el tratamiento; pues salvo fundamentación en contrario las comunicaciones íntimas no tienen por qué incidir en el orden de la prisión.

La sentencia es muy antigua, hoy día seguramente utilizaría el principio de proporcionalidad para analizar la constitucionalidad de la limitación del derecho de intimidad de los presos que supone la restricción de relaciones sexuales.

Como es sabido, este principio significa que la limitación será proporcionada y por tanto constitucional si se adecua a las finalidades penitenciarias que son la garantía de la seguridad, el interés de tratamiento y el buen orden y funcionamiento del centro penitenciario. Además la limitación no podrá ir más allá de lo estrictamente necesario (STC 128/2013, de 3 de junio, FJ 5).

${ }^{34}$ STC 57/1994, de 28 de febrero, FJ5

35 Martínez de Pisón CAVero, J.: El derecho a la intimidad en la jurisprudencia constitucional, Cívitas, Madrid, 1993, p. 190. 
Por tanto la negación de las visitas íntimas hubiera exigido su proporcionalidad, es decir su adecuación a las finalidades penitenciarias de garantía de la seguridad, el interés de tratamiento y el buen orden y funcionamiento del centro penitenciario.

Además el Alto Tribunal, y en aras a la constatación del cumplimiento del principio de proporcionalidad, debería haber revisado la motivación de la medida limitadora del derecho fundamental de intimidad que supuso la negación de visitas íntimas. Es decir el por qué se adoptó la medida, la especificación de cuál de las tres finalidades legalmente previstas -seguridad, interés de tratamiento y buen orden del establecimiento- se persiguió con la adopción de la medida y la explicación de las circunstancias concretas del caso y del recluso que permitieron concluir que la intervención resultase adecuada en orden a alcanzar la finalidad perseguida. (STC 200/1997, de 24 de noviembre, FJ 4).

En definitiva, aunque la sentencia 89/1987, de 3 de junio, niega que las comunicaciones íntimas sean contenido del derecho fundamental de intimidad para el recluso, utiliza el concepto de intimidad en varias dimensiones. Primero, en la dimensión espacial, pues afirma que la autorización para la comunicación íntima restaura circunstancialmente para el recluso un ámbito provisional de intimidad. Segundo, en la dimensión personal, en cuanto las visitas íntimas permiten al recluso la expresión de su sexualidad. En tercer lugar también está presente la intimidad familiar, aquélla compartida con las personas con las que está vinculado, que para las comunicaciones especiales, según establece la legislación penitenciaria, art. 53.LOGP, no sólo pueden ser familiares sino «allegados íntimos».

La segunda de las sentencias aquí estudiadas, la 128/2013, de 3 de junio, caso «visita familiar», contempla un supuesto de hecho consistente en la denegación de una comunicación vis a vis con primos del interno, porque en la solicitud previa de visita hecha por éste, dichos parientes deberían haberse incluido en la categoría de allegados íntimos y no en la de familiares.

La denegación traía causa en la decisión tomada por la dirección del centro penitenciario, de limitar el acceso incondicionado a los parientes dentro del segundo grado, por el gran número de personas que cabía incluir en el concepto de parientes.

Estos parientes, los de parentesco más lejano que el segundo grado, no resultaban excluidos del régimen de visitas. Su visita no podía ser como familiares sino como allegados íntimos con la correspondiente comprobación de su condición.

La distinción entre familiares y allegados fue tomada por la Administración Penitenciaria a los efectos de garantizar el orden y buen funcionamiento del centro, dado el gran número de visitas. 
La sentencia, al enjuiciar constitucionalmente las comunicaciones íntimas de los presos, y a pesar de haber transcurrido más de veinticinco, reitera la fundamentación argüida en la sentencia 89/1987, de 3 de junio, que acabamos de ver.

Sin embargo, se comprueba una evolución de la doctrina constitucional respecto de dicha sentencia. Si en aquella la autorización para la comunicación íntima era el resultado de una concesión del legislador, no un imperativo derivado del derecho fundamental a la intimidad; en ésta se consideran las comunicaciones un derecho que la legislación penitenciaria reconoce al interno: «Ahora bien, la normativa penitenciaria atribuye a todo interno (preso preventivo o penado) el derecho a entablar comunicaciones con otras personas» (FJ 4).

Y deja bien claro que la naturaleza jurídica de este derecho es la de fundamental al aplicar a su limitación, el principio de proporcionalidad. Así es en el fundamento jurídico 5, entra a valorar la adecuación de la limitación de las comunicaciones al principio de proporcionalidad y llega a la conclusión de que la limitación se acomodó al principio de proporcionalidad en cuanto, primero, se adecuó al fin perseguido de garantizar la seguridad y buen funcionamiento del centro penitenciario, y, segundo, la restricción no se extendió más allá de lo estrictamente preciso.

El orden y el buen funcionamiento constituyen finalidades penitenciarias que fueron consideradas proporcionadas por el Tribunal que también consideró la proporcionalidad de la restricción del derecho de visitas que no fue total sino parcial, pues como hemos visto el interno no fue privado de las visitas de sus allegados íntimos sino que el régimen de sus comunicaciones fue sometido a un régimen razonable.

\section{LAS RELACIONES SEXUALES Y LA INTIMIDAD}

En definitiva, nosotros entendemos que las relaciones sexuales, como manifestación de la sexualidad, se integran en la intimidad y por lo tanto son objeto o contenido de este derecho fundamental. En consecuencia su privación es una limitación y una restricción de la sexualidad y por ende del derecho fundamental de intimidad.

Tanto los principios generales de nuestro sistema penitenciario, como los preceptos concretos de su legislación, permiten hablar de un derecho de los internos a mantener contactos con el exterior, a través de comunicaciones y visitas en los establecimientos penitenciarios. Entre los mismos se encuentra la visita íntima como un derecho del recluso para satisfacer sus necesidades sexuales y afectivas.

La propia denominación de estas visitas como «íntimas» nos puede llevar a deducir que el legislador ha querido incluir el mantenimiento de relaciones 
sexuales como contenido del derecho fundamental a la intimidad, pues el posible contenido sexual de una comunicación se incluye en el mayor grado de intimidad posible.

Por tanto, si las comunicaciones son un derecho de los internos, que habilita para éste un espacio y un tiempo reservados frente a la acción y conocimiento de los demás, se puede sostener que las comunicaciones son ejercicio del derecho fundamental de intimidad, y dentro de ellas las visitas de contenido sexual, la máxima expresión de este derecho.

Se comprueba una evolución de la doctrina constitucional. Si en el primer caso que nuestro Tribunal Constitucional debió acercarse a estas cuestiones, la autorización para la comunicación íntima era el resultado de una concesión del legislador, no un imperativo derivado del derecho fundamental a la intimidad, en la más reciente se consideran las comunicaciones un derecho que la legislación penitenciaria reconoce al interno. Y deja bien claro que la naturaleza jurídica de este derecho es la de fundamental al aplicar a su limitación, el principio de proporcionalidad.

\section{TITTLE: The sexuality of prisoners in constitutional jurisprudence}

RESUMEN: El artículo analiza críticamente la doctrina del Tribunal Constitucional sobre la sexualidad de las personas que están en prisión; el Alto Tribunal integra la sexualidad en el ámbito de la intimidad, pero le niega el carácter de derecho fundamental. Frente a esta postura el artículo defiende que las comunicaciones denominadas «intimas», aquellas de contenido sexual, son ejercicio del derecho fundamental de intimidad. Para la defensa de su tesis se fundamenta en la propia Constitución y en la legislación penitenciaria.

PALABRAS CLAVE: Jurisprudencia constitucional. Sentencias 89/1987, de 3 de junio y 28/2013, de 3 de junio. Derecho fundamental de intimidad. Sexualidad. Prisión

ABSTRACT: The paper examines critically the Spanish Constitutional Court doctrine on imprisoned persons sexuality that is contained in the sentences 89/1987 of June the 3rd and 28/2013 June the 3rd. The constitutional judge integrates sexuality in the field of privacy, but denied it as a fundamental right. Opposite to this position, this paper argues that the contacts called «intimate», those with sexual content, are exercising the fundamental right of privacy. The defense of this thesis is based on the Constitution and the penitentiary legislation.

KEYWORDS: Constitutional Court. Sentences 89/1987 of June the 3rd and 28/2013 June the 3rd. Fundamental right to privacy. Sexuality. Prison 